\title{
LETTER
}

\section{Cardiac-related impedance changes obtained by electrical impedance tomography: an acceptable parameter for assessment of pulmonary perfusion?}

\author{
Gerhard Hellige* and Guenter Hahn \\ See related research by Grant et al., http://ccforum.com/content/15/1/R37
}

Electrical impedance tomography has become a tool for monitoring regional ventilation. Interest is growing to derive additional information on pulmonary perfusion and ventilation/perfusion distribution. Since signals recorded by electrical impedance tomography also contain cardiac-related impedance changes, attempts are made to evaluate them in view of perfusion. Recently in Critical Care a corresponding study applying an advanced filtering technique for separating cardiac signals from the dominant ventilation component was published [1]. The quality of the concept is demonstrated by comparing the results with solitary cardiac signals during breath-hold.

Similar to other publications dealing with this approach, the correct term cardiac-related impedance changes is substituted by perfusion. Although major aspects of limitations and missing validation are addressed in the discussion, the key message presented is that it is possible to distinguish between lung ventilation and perfusion using electrical impedance tomography'.

Vascular volume pulses which are the reasons for cardiac-related impedance changes in the lung area obviously do not unequivocally represent perfusion. Even peripherally occluded arteries will pulsate without flow. These pulsations are dependent on blood pressure and vascular as well as surrounding tissue compliance.

A reasonable approach to assess perfusion by electrical impedance tomography is the impedance indicator dilution technique, which is clearly favoured by recent publications [2-4]. In contrast to the questionable pulsation approach, a homogeneous distribution of perfusion and ventilation/perfusion ratios was obtained [5].

In summary, the interpretation of cardiac-related impedance changes in view of perfusion will not be permissible until validation by established reference techniques including relevant pathophysiological conditions.

\section{Competing interests}

The authors declare that they have no competing interests.

Published: 1 June 2011

\section{References}

1. Grant CA, Pham T, Hough J, Riedel T, Stocker C, Schibler A: Measurement of ventilation and cardiac related impedance changes with electrical impedance tomography. Crit Care 2011, 15:R37.

2. Costa E, Lima R, Amato M: Electrical impedance tomography. Curr Opin Crit Care 2009, 15:18-24.

3. Muders T, Luepschen $H$, Putensen C: Impedance tomography as a new monitoring technique. Curr Opin Crit Care 2010, 16:269-275.

4. Luepschen H, Muders T, Pikkemaat R, Meier T, Putensen C, Leonhardt S: Determination of lung perfusion using electrical impedance tomography. Biomed Tech 2010, 55 (Suppl 1):104-107.

5. Hellige G, Dittmar J, Just A, Hahn G: Monitoring of pulmonary perfusion distribution by electrical impedance tomography. Biomed Tech 2010, 55(Suppl 1):31-34.

doi:10.1186/cc10231

Cite this article as: Hellige G, Hahn G: Cardiac-related impedance changes obtained by electrical impedance tomography: an acceptable parameter for assessment of pulmonary perfusion? Critical Care 2011, 15:430. 